\title{
The Comparative Associations of Ultrasound and Computed Tomography Estimates of Muscle Quality with Physical Performance and Metabolic Parameters in Older Men
}

\author{
Michael O. Harris-Love 1,2,3,*(D, Nilo A. Avila ${ }^{4,5}$, Bernadette Adams ${ }^{1,3}$, June Zhou ${ }^{3,6}$, \\ Bryant Seamon ${ }^{1}$ (), Catheeja Ismail ${ }^{1,7}$, Syed H. Zaidi ${ }^{4}$, Courtney A. Kassner ${ }^{4}$, Frank Liu ${ }^{8}$ and \\ Marc R. Blackman 3,6,7,9 \\ 1 Muscle Morphology, Mechanics, and Performance Laboratory, Geriatrics Service, Veterans Affairs Medical \\ Center, Washington, DC 20422, USA; blpadams@gmail.com (B.A.); seamon@musc.edu (B.S.); \\ 34Cath@gmail.com (C.I.) \\ 2 Milken Institute School of Public Health, The George Washington University, Washington, DC 20052, USA \\ 3 Research Service, Veterans Affairs Medical Center, Washington, DC 20422, USA; June.Zhou@va.gov (J.Z.); \\ Marc.Blackman@va.gov (M.R.B.) \\ 4 Radiology Service, Veterans Affairs Medical Center, Washington, DC 20422, USA; \\ nilo.avila@nih.gov (N.A.A.); Syed.Zaidi2@va.gov (S.H.Z.); Courtney.Kassner@va.gov (C.A.K.) \\ 5 Cardiovascular and Pulmonary Branch, National Heart, Lung, and Blood Institute, The National \\ Institutes of Health, Bethesda, MD 20892, USA \\ 6 Department of Biochemistry \& Molecular Medicine, The George Washington University, Washington, \\ DC 20037, USA \\ 7 Department of Medicine, The George Washington University, Washington, DC 20052, USA \\ 8 Nuclear Medicine Section, Veterans Affairs Medical Center, Washington, DC 20422, USA; Frank.Liu2@va.gov \\ 9 Departments of Medicine and Rehabilitation Medicine, Georgetown University School of Medicine, \\ Washington, DC 20007, USA \\ * Correspondence: mhl@gwu.edu; Tel.: +1-202-745-8000 (ext. 57640)
}

Received: 23 September 2018; Accepted: 8 October 2018; Published: 10 October 2018

\begin{abstract}
Estimates of muscle tissue composition may have greater prognostic value than lean body mass levels regarding health-related outcomes. Ultrasound provides a relatively low cost, safe, and accessible mode of imaging to assess muscle morphology. The purpose of this study was to determine the construct validity of muscle echogenicity as a surrogate measure of muscle quality in a sample of older, predominantly African American (AA) participants. We examined the association of rectus femoris echogenicity with mid-thigh computed tomography (CT) scan estimates of intra- and intermuscular adipose tissue (IMAT), basic metabolic parameters via blood sample analysis, muscle strength, and mobility status. This observational study was conducted at a federal medical center and included 30 community-dwelling men (age, $62.5 \pm 9.2$; AA, $n=24$; Caucasian, $n=6$ ). IMAT estimates were significantly associated with echogenicity $(r=0.73, p<0.001)$. Echogenicity and IMAT exhibited similar associations with the two-hour postprandial glucose values and high-density lipoproteins values $(p<0.04)$, as well as grip and isokinetic $\left(180^{\circ} / \mathrm{s}\right)$ knee extension strength adjusted for body size $(p<0.03)$. The significant relationship between ultrasound and CT muscle composition estimates, and their comparative association with key health-related outcomes, suggests that echogenicity should be further considered as a surrogate measure of muscle quality.
\end{abstract}

Keywords: aging; muscle tissue composition; echogenicity; sarcopenia; muscle quality; quantitative ultrasound; computed tomography; muscle strength; metabolic status; myosteatosis 


\section{Introduction}

The maintenance of adequate lean body mass (LBM) with increasing age remains an important determinant of physical health, especially in older individuals who undergo surgical procedures or have extended hospital stays [1,2]. It has been known for nearly two decades that poor skeletal muscle tissue composition is often a better predictor of muscle performance than LBM in ambulatory older adults [3,4]. Nevertheless, this research insight has not been effectively integrated into medical practice. This is largely due to the cost and access constraints associated with the use of computed tomography (CT) and magnetic resonance imaging (MRI) for the assessment of body composition or age-related muscle dysfunction [5,6]. Given the importance of both LBM and skeletal muscle tissue composition to understanding and assessing sarcopenia, many investigators have proposed the use of diagnostic musculoskeletal ultrasound as an alternative imaging approach [7-9].

Muscle echogenicity has been previously proposed as a method to estimate muscle tissue composition $[10,11]$. Quantitative ultrasound measures of echogenicity denote image brightness caused by the reflection of soundwaves and influenced by sound beam characteristics and tissue density [12]. While echogenicity measures have been associated with intra- and intermuscular fat in older adults and children with neuromuscular disease, hyperechoic tissue may also mark other non-contractile elements of skeletal muscle [13-15]. However, findings utilizing biopsied muscle tissue reveal that echogenicity has a significant positive association with the proportion of intramuscular fat in a sample of people with neuromuscular disease [16]. Recent data also suggest that echogenicity is associated with extramyocellular lipids based on mid-thigh T1-weighted MRI and ${ }^{1} \mathrm{H}$ magnetic resonance spectroscopy $\left({ }^{1} \mathrm{H}\right.$ MRS) data obtained from young and old adults [17]. Additionally, preliminary reports indicate that echogenicity estimates of anterior mid-thigh muscles may be associated with corresponding CT scan attenuation at the region of interest (ROI) in a sample of community-dwelling women [13].

The use of quantitative ultrasound to measure muscle echogenicity has been employed to aid the diagnosis of neuromuscular disease [14], estimate post-exercise intervention changes in muscle composition [18], and identify adults with age-related muscle dysfunction [19]. Importantly, there is strong evidence for the inverse association between muscle echogenicity and muscle strength in both older men and women [20,21], and early findings suggest that rectus femoris echogenicity may aid the clinical identification of sarcopenia [19]. Relative measures of strength are increasingly recognized as a domain of "muscle quality" $[11,22,23]$. Consequently, surrogate measures of muscle quality such as echogenicity may help to identify those with an elevated risk of strength impairment and functional decline. Estimates of muscle strength and tissue composition have demonstrated greater prognostic value than LBM levels regarding health-related outcomes [23]. In addition, extramyocellular (i.e., intra- and intermuscular adipose tissue) and intramyocellular lipids may partially contribute to declines in muscle strength that are not attributable to a loss of muscle mass alone $[3,17]$. Therefore, practical and reliable methods of detecting poor muscle tissue composition that affect muscle performance, but precede the appreciable decline of LBM, have clinical value. Given the increased risk for hospitalization and cardiovascular disease mortality associated with poor muscle tissue composition $[23,24]$, quantitative ultrasound morphology measures may have a role in the management of patients with certain geriatric syndromes [9].

The purpose of this study was to determine the construct validity of muscle echogenicity as a surrogate measure of muscle quality in a sample of older, predominantly African American men. Construct validity was examined based on the association of rectus femoris echogenicity with mid-thigh CT scan estimates of intra- and intermuscular adipose tissue (IMAT), basic metabolic parameters via blood sample analysis, muscle strength, and mobility status. 


\section{Methods}

\subsection{Study Design}

This study featured a prospective, single group, observational design to evaluate the construct validity of estimating muscle tissue composition using quantitative ultrasound. The study included a sample of convenience and was conducted in a clinical environment at a federal medical center. Data were collected by staff in the Physical Medicine and Rehabilitation, Pathology and Laboratory Medicine, Research Service Laboratory and Nuclear Medicine and Radiology service groups at the Veterans Affairs Medical Center in Washington, DC (DC VAMC).

\subsection{Study Participants}

Community-dwelling veteran men were screened at the medical center for potential enrollment into the Age-Related Muscle Dysfunction Screening Study (ARMS Study I). The ARMS Study I was approved separately by the DC VAMC Institutional Review Board and the Research and Development Committee. Inclusion criteria for study enrollment included being an ambulatory male veteran between 45 and 85 years of age. Exclusion criteria included recent hospitalization (within 3 months), uncontrolled cardiovascular disease, limb amputation, medical conditions that result in edema, and musculoskeletal or neurological disorders (e.g., cerebrovascular accident resulting in hemiparesis or intrinsic muscle disease) that are associated with muscle atrophy.

A clinical research nurse screened 104 study candidates at the medical center and 30 individuals qualified for participation in the study. Screening failures during study recruitment were due to uncontrolled cardiovascular or metabolic disease $(n=38)$, recent hospitalizations $(n=16)$, conditions that may confound dual-energy X-ray absorptiometry (DXA) findings (e.g., edema, major joint replacement, or body stature; $n=7)$, age outside of the study inclusion range $(n=5)$, and qualified individuals unable or unwilling to fully participate for other reasons $(n=8)$. Upon obtaining written informed consent, all participants completed the imaging examinations, strength tests, functional assessments, anthropometric measures, and blood sampling. Outcome measures were completed over the course of 2 visits (with a span of 10 days or less between visits), and imaging procedures were always performed on a separate visit from the physical performance tests.

\subsection{Outcome Measures}

The clinical reference standards for body composition and muscle tissue composition estimates in this study were DXA and CT scanning, respectively $[5,25,26]$. The CT scans, and corresponding ultrasound scans, were taken at the anterior mid-thigh given the previous use of this site to estimate IMAT [3,27-30]. The physical status of the participants was represented by performance-based assessments. The primary measures of general physical performance and mobility were peak force from hand grip dynamometry and gait speed derived from the 10-m walk test given the extensive use of these assessments in clinical trials involving ambulatory older adults [26,31]. In addition, peak knee extensor torque was used to characterize muscle performance of the anterior thigh muscle groups included in the imaging examinations [29,30,32]. Basic biomarkers of metabolic health were assessed via a lipid panel and fasting insulin/glucose levels taken from a blood sample [33].

\subsubsection{Tissue and Body Composition Analyses}

A portable, diagnostic ultrasound device (SonoSite M-Turbo 1.1.2; SonoSite, Inc., Bothell, WA, USA) with a 13.6 MHz linear array transducer was used for B-mode scanning and image acquisition. Time gain compensation, and well as near field/far field gain, remained at the manufacturer default settings for musculoskeletal scanning. The field of view was adjusted for each participant to optimally capture the ROI for the rectus femoris. Water-soluble transmission gel was used during scanning to maintain adequate acoustic contact with the skin surface, and minimal examiner pressure was used during the scanning to avoid tissue deformation prior to image capture. The dominant-side scanning 
site and procedures used in this study have been previously reported by the authors [19]. Briefly, surface anatomy landmarks were identified at the anterior superior iliac spine and the superior pole of the patella. The bisected distance $(\mathrm{cm})$ between the surface landmarks were measured using a non-elastic weighted tape measure and marked with an indelible ink pen. Quantitative ultrasound imaging was performed with the participants seated with their feet on the floor and their elbows, hips, and knees were positioned at $90^{\circ}$ of flexion. All scanned images were obtained and measured 3 times within the fascial boarders of the muscle. The ROI selection and echogenicity measures of the rectus femoris via grayscale histogram analysis were completed using ImageJ (version 1.48; National Institutes of Health, Bethesda, MD, USA) [34]. A single clinical investigator with over 10 years of quantitative ultrasound experience acquired the scanned images and obtained the echogenicity measures (echogenicity expressed as grayscale levels (GSL) within a unitless range of $0-255$ ). This scanning procedure and image analysis approach has been shown to have good reliability in our facility (lower bound $95 \%$ confidence interval (CI) intraclass correlation coefficient $\left(\mathrm{ICC}_{2, k}\right)=0.97-0.99, p<0.001$, standard error of measurement, $\mathrm{SEM}=1.05$ grayscale levels) [27].

Estimates of IMAT were obtained via CT imaging at the mid-thigh (Siemens 64; $\mathrm{SD}=0.2$ Hounsfield units $(\mathrm{HU})$, coefficient of variation, $\mathrm{CV}=0.005)$. A single $10 \mathrm{~mm}$ axial image slice $(120 \mathrm{kVp}$, 200 to $250 \mathrm{~mA}$ ) of the thigh was obtained on the dominant limb. The scanning site for ultrasound and $\mathrm{CT}$ imaging were at a common location identified during the ultrasound examination. The mid-thigh target location marked with indelible ink was covered with a radiopaque marker prior to the CT scanning session. An anterior-posterior scout scan of the entire femur was completed followed by an axial scan featuring the marker to verify the ROI. Upon verification of the scanning location, a second image was acquired without the marker for the subsequent image analyses. A radiologist and study co-investigator (N.A.) performed the initial review of the CT scans. Image processing and analysis of the CT scans for tissue segmentation was performed using ImageJ. The primary investigator (M.H.L) completed the tissue segmentation procedure in consultation with the radiologist. The deep fascial layer was digitized prior to calculating estimates for the proportion of cross-sectional area (CSA) subcutaneous fat, and IMAT [3]. All tissue composition estimates were adjusted to not include pixel values derived from cortical bone, medullary fat, or potential confounders for LBM within the dermal layers. Tissue analyzed in the ROI within +31 to $+100 \mathrm{HU}$ range was classified as normal density muscle, and tissue in the 0 to $+30 \mathrm{HU}$ range was classified as low-density muscle affected by intramuscular adipose tissue [35]. Tissue in the -190 to $-30 \mathrm{HU}$ range was denoted as adipose tissue with further classification as subcutaneous fat or intermuscular fat based on its location relative to the deep fascial layer and intermuscular septa of the thigh musculature [3].

Estimates of LBM via whole body DXA imaging using a GE Lunar iDXA machine (GE Medical Systems Ultrasound and Primary Care Diagnostics, LLC, Madison, WI, USA) were completed by a trained radiology technician. Height $(\mathrm{cm})$ was measured with a stadiometer and body mass $(\mathrm{kg})$ was measured with a balance scale prior to body composition testing. Body mass index (BMI) was calculated as weight $(\mathrm{kg}) /$ height $\left(\mathrm{m}^{2}\right)$. Total body fat values were recorded, and LBM estimates were calculated as the sum of fat-free mass in the arms and legs (aLM) and scaled to height (aLM/ht $\left.{ }^{2}\right)$. The preparation and positioning of the participant was performed according to the DC VAMC Radiology Service testing procedures. All DXA scans were obtained on the same day as the quantitative ultrasound session.

\subsubsection{Blood Sampling: Metabolic Parameters}

Following an overnight fast, the metabolic parameters were measured from venous blood samples withdrawn from an antecubital vein. Serum glucose and lipid concentrations were measured by routine methods in the Clinical Laboratory Improvement Amendments certified Clinical Pathology Laboratory of the Washington DC VA Medical Center. Serum insulin was measured in the Research Laboratory of Geriatric Endocrinology and Metabolism. 


\section{Oral Glucose Tolerance Test (OGTT)}

Venous blood samples $(10 \mathrm{~mL})$ were obtained before and $2 \mathrm{~h}$ after oral ingestion of a $75 \mathrm{~g}$ oral glucose solution. Whole blood samples were allowed to clot for 5-10 $\mathrm{min}$, centrifuged for $10 \mathrm{~min}$ at $2000 \times g$, and the resultant serum stored at $-80{ }^{\circ} \mathrm{C}$ in aliquots until assayed. Interpretation of the oral glucose tolerance test (OGTT) two-hour postprandial glucose values were as follows: normal < $140 \mathrm{mg} / \mathrm{dL}$; impaired glucose tolerance 140-199 mg/dL; diabetic $\geq 200 \mathrm{mg} / \mathrm{dL}$.

Glucose and Insulin

Serum glucose was assayed using the hexokinase method utilizing the glucose-6-phosphate dehydrogenase and colorimetric reading. Test results were interpreted per the American Diabetes Association Diagnostic criteria: normal < $100 \mathrm{mg} / \mathrm{dL}$, pre-diabetic 100-125 mg/dL; diabetic $>125 \mathrm{mg} / \mathrm{dL}$. Serum concentrations of insulin were measured by enzyme-linked immunosorbent assay (ELISA) (Millipore Sigma Corporation, Catalog No. EZHI-14K) following procedures recommended by the manufacturer. This sandwich assay is based, sequentially, on: (1) capture of human insulin molecules from samples to the wells of a microtiter plates coated by a pre-titered amount of monoclonal mouse anti-human insulin antibodies and the binding of a second biotinylated monoclonal mouse anti-human antibody to the captured insulin, (2) washing away of unbound materials from samples, (3) conjugation of horseradish peroxidase to the immobilized biotinylated antibodies, (4) washing away of free enzyme conjugates, and (5) quantification of immobilized antibody-enzyme conjugates by monitoring horseradish peroxidase activities in the presence of the substrate $3,3^{\prime}, 5,5^{\prime}$-tetramethylbenzidine. The enzyme activity is measured spectrophotometrically after acidification of formed products.

All samples were assayed in duplicate, with sensitivity $(1 \mu \mathrm{U} / \mathrm{mL})$, range $(2 \mu \mathrm{U} / \mathrm{mL}$ to $200 \mu \mathrm{U} / \mathrm{mL})$, intra-assay CV (4.6-7.0\%) and inter-assay CV (9.1-11.4\%) within the limits indicated by the manufacturer. Normal fasting serum insulin concentrations are $<25-30 \mu \mathrm{U} / \mathrm{mL}$. Quantitative insulin sensitivity check index (QUICKI) was calculated as $1 /\left[\log \left(\mathrm{I}_{0}\right)+\log \left(\mathrm{G}_{0}\right)\right]$, where $\mathrm{I}_{0}$ was the fasting insulin value, and $\mathrm{G}_{0}$ was the fasting glucose value.

Lipids

Lipid assays were performed on a Roche Cobas c501 System following procedures recommended by the manufacturer. Total cholesterol was measured by a timed end point method in which cholesterol esterase hydrolyzes cholesterol esters to free cholesterol and fatty acids. Free cholesterol is oxidized to cholestene-3-one and hydrogen peroxide by cholesterol oxidase. Peroxidase catalyzes the reaction of hydrogen peroxide with 4-aminoantipyrine and phenol to produce a colored quinoneimine product. The Roche cholesterol assay meets the 1992 National Institutes of Health (NIH) goal of less than or equal to $3 \%$ for both precision and bias. Normal total cholesterol level is $<200 \mathrm{mg} / \mathrm{dL}$.

The high-density lipoproteins (HDL) assay involves elective formation of water-soluble complexes between dextran sulfate and low-density lipoproteins (LDL), very low density lipoprotein and chylomicrons which are resistant to PEWG-modified enzymes used in the subsequent enzymatic steps leading to formation of a colored product. Calculated LDL levels were determined according to Friedewald's formula. The laboratory normal HDL range was $>35 \mathrm{mg} / \mathrm{dL}$, and the range was $\leq 130 \mathrm{mg} / \mathrm{dL}$ for LDL.

Triglycerides are measured in a timed end-point method in which triglycerides are hydrolyzed to glycerol and free fatty acids by the action of lipase, followed by three enzymatic steps catalyzed by glycerol kinase, glycerophosphate oxidase, and horseradish peroxidase which lead to the formation of a colored product. The laboratory normal triglyceride range was $60-190 \mathrm{mg} / \mathrm{dL}$. 


\subsubsection{Physical Performance: Strength and Mobility}

The construct of "strength" was represented by the averaged peak force or torque values scaled to body weight given the well-known influence of body size on the expression of unadjusted strength values [36-38]. Upper extremity strength was assessed using hand grip dynamometry (Jamar, Lafayette Instruments, Lafayette, IN, USA). The test proctor provided a demonstration of the dynamometer and allowed the participant to have one to two practice attempts prior to recording peak force data. The mean value of three trials under standardized conditions were used for data collection [39]. Grip strength is a common measure of muscle function in older adults and a preferred method of strength assessment for sarcopenia clinical trials [26]. The Jamar dynamometer has exhibited high reliability (ICCs $=0.97-0.98, p<0.01$ ) in previous studies [40]. Lower extremity strength was assessed using an isokinetic dynamometer (Biodex System 4, Biodex Medical Systems, Shirley, NY, USA). Knee extensor strength was assessed at isokinetic speeds of $60^{\circ} / \mathrm{s}$ and $180^{\circ} / \mathrm{s}$ using methods adapted from previously published protocols [41,42] with patient positioning and stabilization per the Biodex Operations Manual. Participants were oriented to the visual feedback for the torque-time curve displayed on the computer monitor, and provided with a familiarization session, prior to data collection. Strength data were compiled from the mean value of the highest three peak torque values from a five-repetition test. Previous investigators have found this form of strength assessment to be reliable (ICC $=0.92)$, and the standard error of the mean (SEM) is approximately $8 \%$ in older adults $[42,43]$. In addition, gait speed was used to characterize mobility in this study. The gait speed test is perhaps the most common screening test used for sarcopenia [26]. The 10-m walk test included in this study was recorded with a stop watch and adapted from the methods of Bohannon et al. and others $[44,45]$.

\section{Statistical Analysis}

Descriptive statistics were used to convey the outcome measures and participant characteristics. Data were expressed as means and standard deviations if they had normal data and variance distributions. Otherwise, data were expressed as median values with the interquartile range (IQR) [46]. Inferential statistics were used to examine the construct validity of muscle echogenicity as a surrogate measure of muscle quality. Pearson product-moment correlation coefficients (PMCC, $r$ ) were used to determine the associations among the estimates of body composition, metabolic parameters, muscle tissue composition, and physical performance. Significant bivariate relationships between the muscle tissue composition estimates and metabolic parameters were identified using the PMCC and further examined while adjusting for the influence of known IMAT covariates: age and total body fat [47,48]. Multiple linear regression was used to assess the conditional association between estimates of muscle tissue composition and selected metabolic parameters using standardized beta coefficients. The $\mathrm{F}$ values from an analysis of covariance were used to assess the integrity of each multiple linear regression equation. The strength of the association among the correlation coefficients was determined using criteria noted by Portney and Watkins [46].

Independent $\mathrm{t}$-tests were used to determine if preliminary cutoff values for muscle tissue composition estimates could discriminate between participants with high or low strength performance. These analyses were conducted using criterion values from the first and third tertiles of IMAT and echogenicity GSL values. This strategy was employed since there is no standard cutoff value for muscle tissue composition estimates. Additionally, our previous work suggests that the residuals associated with the bivariate relationship between GSL values and scaled strength values are largest within the second tertile [19]. It was presumed that study findings showing a significant relationship for GSL values with metabolic parameters, IMAT estimates, and physical performance would support the construct validity of muscle echogenicity as a surrogate measure of muscle quality [49]. Construct validity would be further supported by significant differences in strength values based on first and third GSL tertiles of muscle echogenicity. 
Power analyses were completed using $G^{*}$ Power (version 3.0.10) with $\alpha$ set at 0.05 for all estimates. The analyses regarding the association between echogenicity and IMAT were informed by our interim cohort analysis [50] based on the $F$ test model for linear multiple regressions with three predictor variables featuring a random model approach $\left(\rho^{2}=0.64\right)$. This yielded a $\beta$ value of 0.83 and a required sample size of 15 . The analyses regarding the association between echogenicity and strength were informed by preliminary data from our group [51] involving multiple scanning sites and grip strength $\left(\rho^{2}=0.27-0.54\right)$, which results in $\beta$ values of $0.80-0.84$ and a sample size range of $14-31$. Study power for difference analyses were based on the $t$ test model for independent groups. The observed effect sizes $(d=1.07-1.14)$ were derived from our previously reported data concerning echogenicity and grip strength in participants with and without sarcopenia [19]. These calculations yielded a sample size estimate of 28-30 participants. Statistical analyses were performed using SPSS statistical software for Windows (version 10.0, SPSS Inc., Chicago, IL, USA). Data with a non-normal distribution were $\log$ transformed prior to statistical analyses involving bivariate relationships. Levene's test was used for analysis of differences involving data with non-normal distributions of variance, and two-tailed $p$ values $<0.05$ were considered significant for all inferential statistics.

\section{Results}

Our final study population consisted of 30 veterans who were primarily older African-American men (average age: $62.5 \pm 9.2$ years). A complete description of the participants' characteristics is provided in Table 1. In general, our sample was overweight (BMI: $26.3 \pm 3.8$ ) and had a high total body fat percentage (BF\%: $27.8 \pm 7.4 \%$ ). In terms of physical performance and mobility, our sample performed relatively well with both grip strength and gait speed falling within normal limits for healthy older adults [52,53]. Additionally, the average values for metabolic parameters fell within normal values for healthy individuals based on reference values used at the study site medical center.

Table 1. Participant characteristics.

\begin{tabular}{|c|c|}
\hline \multicolumn{2}{|c|}{ Participant Characteristics $(n=30)$} \\
\hline Age (years) & $62.5 \pm 9.2$ \\
\hline \multicolumn{2}{|l|}{ Racial/ethnic group } \\
\hline African American & $24(80.0 \%)$ \\
\hline Caucasian & $6(20.0 \%)$ \\
\hline Body mass index & $26.3 \pm 3.8$ \\
\hline Echogenicity (GSL) ${ }^{a}$ & $31.67 \pm 9.41$ \\
\hline \multicolumn{2}{|l|}{ Body composition $\mathrm{b}$} \\
\hline $\mathrm{aLM} / \mathrm{ht}^{2}\left(\mathrm{~kg} / \mathrm{m}^{2}\right)$ & $8.57 \pm 1.12$ \\
\hline Body fat $(\%)$ & $27.8 \pm 7.4$ \\
\hline \multicolumn{2}{|c|}{ Muscle tissue composition (mid-thigh CSA) ${ }^{c}$} \\
\hline Lean mass $(\%)$ & $53.1 \pm 12.1$ \\
\hline Subcutaneous fat (\%) & $28.6 \pm 8.3$ \\
\hline IMAT $(\%)$ & $17.1(14.18,22.56)$ \\
\hline \multicolumn{2}{|l|}{ Muscle strength ${ }^{d}$} \\
\hline Grip strength $0^{\circ} / \mathrm{s}(\mathrm{kg})$ & $39.5 \pm 9.2$ \\
\hline Grip strength $0^{\circ} / \mathrm{s}$ (Adj.) & $0.49 \pm 0.98$ \\
\hline Knee extensors $60^{\circ}$ / s (Nm) & $194.8 \pm 65.7$ \\
\hline Knee extensors $60^{\circ}$ /s (Adj.) & $0.58 \pm 0.16$ \\
\hline Knee extensors $180^{\circ} / \mathrm{s}(\mathrm{Nm})$ & $126.2 \pm 50.7$ \\
\hline Knee extensors $180^{\circ} / \mathrm{s}$ (Adj.) & $0.37 \pm 0.12$ \\
\hline \multicolumn{2}{|l|}{ Mobility } \\
\hline Customary gait speed (m/s) & $1.23 \pm 0.34$ \\
\hline Fast gait speed $(\mathrm{m} / \mathrm{s})$ & $1.62 \pm 0.41$ \\
\hline
\end{tabular}


Table 1. Cont.

\begin{tabular}{lc}
\hline \multicolumn{2}{c}{ Participant Characteristics $(\boldsymbol{n}=\mathbf{3 0})$} \\
\hline Metabolic parameters & \\
OGTT $(\mathrm{mg} / \mathrm{dL}) \mathrm{e}$ & $105.00(77.75,123.50)$ \\
Insulin $(\mathrm{mg} / \mathrm{dL})$ & $3.74(2.72,6.78)$ \\
Glucose $(\mathrm{uM} / \mathrm{mL})$ & $92.00(88.00,99.25)$ \\
QUICKI & $0.39(.36,0.41)$ \\
TC $(\mathrm{mg} / \mathrm{dL})$ & $185.15 \pm 37.79$ \\
LDL (mg/dL) & $114.50 \pm 36.80$ \\
HDL $(\mathrm{mg} / \mathrm{dL})$ & $54.45 \pm 13.48$ \\
TG $(\mathrm{mg} / \mathrm{dL})$ & $81.92 \pm 32.99$ \\
\hline
\end{tabular}

Parametric data are expressed as mean values $\pm \mathrm{SD}$, and non-parametric data are expressed as median values and interquartile range. GSL, grayscale levels (unitless); aLM, appendicular lean mass; CSA, cross-sectional area; IMAT, intra- and intermuscular adipose tissue; Adj., adjusted; OGTT, oral glucose tolerance test; QUICKI, quantitative insulin sensitivity check index; TC, total cholesterol; HDL, high-density lipoproteins, LDL, low-density lipoproteins; TG, triglycerides. ${ }^{a}$ Echogenicity obtained from the rectus femoris of the dominant limb. ${ }^{b}$ Body composition estimated using dual-energy X-ray absorptiometry (DXA). ${ }^{c}$ IMAT and subcutaneous fat values derived from computed tomography attenuation at the mid-thigh of the dominant limb. ${ }^{d}$ All strength values reported for the dominant limb with the adjusted values scaled for body weight. ${ }^{\text {e }}$ OGTT two-hour postprandial glucose values.

\subsection{Surrogate Measures of Muscle Quality and Body Composition Estimates}

Muscle composition estimates served as surrogate measures of muscle quality. These estimates were derived from images obtained at the mid-thigh via $\mathrm{CT}$ and ultrasound scanning at the same anatomical plane of measurement. IMAT estimates from the mid-thigh CT scans were strongly associated with echogenicity measures from the rectus femoris $(r=0.73, p<0.001)$. Echogenicity and IMAT both exhibited significant direct relationships with mid-thigh CSA subcutaneous fat and total body fat estimates. The relationships among surrogate measures of muscle quality and body composition estimates are reported in Table 2.

Table 2. Associations among surrogate measures of muscle quality and body composition estimates.

\begin{tabular}{|c|c|c|c|c|c|c|}
\hline & & Echogenicity $^{a}$ & IMAT $^{b}$ & $\begin{array}{l}\text { Subcutaneous } \\
\text { Fat }^{b}\end{array}$ & $\begin{array}{c}\text { Total Body } \\
\text { Fat }^{c}\end{array}$ & $\begin{array}{l}\text { Lean Body } \\
\text { Mass }\end{array}$ \\
\hline \multirow[t]{2}{*}{ Echogenicity $^{a}$} & $r$ & 1 & 0.73 & 0.47 & 0.51 & -0.29 \\
\hline & p-value & & $<0.001^{*}$ & 0.008 * & 0.004 * & 0.126 \\
\hline \multirow[t]{2}{*}{$\mathrm{IMAT}^{\mathrm{b}}$} & $r$ & & 1 & 0.38 & 0.54 & 0.03 \\
\hline & $p$-value & & & $0.038 *$ & $0.002 *$ & 0.882 \\
\hline Subcutaneous fat ${ }^{b}$ & $p$-value & & & & $<0.001$ & 0.553 \\
\hline \multirow[t]{2}{*}{ Total body fat ${ }^{c}$} & $r$ & & & & 1 & 0.18 \\
\hline & p-value & & & & & 0.328 \\
\hline \multirow[t]{2}{*}{ Lean body mass ${ }^{d}$} & $r$ & & & & & 1 \\
\hline & $p$-value & & & & & \\
\hline
\end{tabular}

IMAT, intra- and intermuscular adipose tissue; Adj., adjusted; Ext., extensors; ${ }^{*} p<0.05 .{ }^{a}$ Echogenicity obtained from the rectus femoris of the dominant limb and measured via grayscale histogram analysis. ${ }^{b}$ IMAT and subcutaneous fat values derived from computed tomography attenuation at the mid-thigh of the dominant limb; log transformed data used in the analysis. ${ }^{c}$ Total body fat estimated using dual-energy X-ray absorptiometry (DXA). ${ }^{d}$ Lean body mass is appendicular lean mass scaled to height $\left(\mathrm{aLM} / \mathrm{ht}^{2}\right)$.

\subsection{Surrogate Measures of Muscle Quality, Body Composition, and Metabolic Parameters}

Muscle echogenicity and IMAT both exhibited significant direct relationships with the OGTT two-hour postprandial glucose values and inverse associations with high-density lipoproteins (HDL) values. Echogenicity demonstrated the strongest positive association with OGTT $(r=0.43, p=0.018)$, and IMAT had the strongest negative relationship with HDL values $(r=-0.61, p<0.001)$. However, total body fat also exhibited significant, comparable associations with these metabolic parameters. In addition, LBM was directly associated with fasting glucose levels $(r=-0.46, p<0.023)$, but not with 
fasting insulin levels or the OGTT results $(p>0.05)$. The relationships among surrogate measures of muscle quality, body composition estimates, and general metabolic parameters are provided in Table 3.

Given the significant associations of surrogate measures of muscle quality with postprandial glucose values and HDL results, we selected these two metabolic parameters as dependent variables in multiple linear regression models to adjust for the known covariates: age and total body fat. IMAT retained a moderate association with the postprandial glucose values when accounting for age and total body fat (Age: $\beta=-0.006, \mathrm{BF} \%: \beta=0.184$, IMAT: $\beta=0.405 ; \mathrm{F}=3.06, p=0.046$ ). IMAT demonstrated a similar association with HDL as the dependent variable in the model (Age: $\beta=0.237, \mathrm{BF} \%$ : $\beta=-0.444$, IMAT: $\beta=-0.461 ; \mathrm{F}=7.30, p=0.001$ ). The associations for echogenicity were comparable to IMAT when examining the same metabolic parameters and covariates. Specifically, echogenicity (expressed as GSL) retained a moderate association with the HDL results when accounting for age and total body fat (Age: $\beta=0.166, \mathrm{BF} \%: \beta=-0.434, \mathrm{GSL}: \beta=-0.395 ; \mathrm{F}=6.62$, $p=0.002)$. We found echogenicity to be a moderate contributor to the model for postprandial glucose values with either age as a co-variate (Age: $\beta=0.038$, GSL: $\beta=0.460 ; \mathrm{F}=4.10, p=0.028$ ) or total body fat as a co-variate (BF\%: $\beta=0.162$, GSL: $\beta=0.400 ; \mathrm{F}=4.54, p=0.020)$. However, the model for echogenicity as predictor variable for HDL was not significant when adjusting for both age and total adiposity $(\mathrm{F}=2.93, p=0.052)$.

Table 3. Associations among surrogate measures of muscle quality, body composition estimates, and metabolic parameters.

\begin{tabular}{|c|c|c|c|c|c|c|c|c|c|}
\hline & & Insulin $^{c}$ & Glucose $^{c}$ & QUICKI $^{c}$ & OGTT $^{c, f}$ & TC & LDL & HDL & TG \\
\hline Echogenicity $^{a}$ & p-value & 0.438 & 0.116 & 0.161 & 0.018 * & 0.114 & 0.496 & 0.003 * & 0.875 \\
\hline IMAT $^{b, c}$ & p-value & 0.825 & 0.514 & 0.57 & 0.038 * & 0.550 & 0.745 & $<0.001$ * & 0.237 \\
\hline \multirow[t]{2}{*}{ Subcutaneous fat ${ }^{b}$} & $r$ & 0.15 & -0.24 & -0.17 & 0.12 & 0.05 & 0.14 & -0.27 & 0.02 \\
\hline & p-value & 0.438 & 0.255 & 0.44 & 0.519 & 0.799 & 0.465 & 0.155 & 0.937 \\
\hline Total body fat ${ }^{\mathrm{d}}$ & p-value & 0.751 & 0.327 & 0.44 & $0.029 *$ & 0.738 & 0.265 & $0.001 *$ & 0.061 \\
\hline \multirow[t]{2}{*}{ Lean body mass ${ }^{\mathrm{e}}$} & $r$ & 0.17 & 0.46 & -0.28 & -0.13 & 0.30 & 0.33 & -0.11 & 0.17 \\
\hline & p-value & 0.401 & 0.023 * & 0.20 & 0.503 & 0.111 & 0.076 & 0.574 & 0.382 \\
\hline
\end{tabular}

QUICKI, Quantitative Insulin Sensitivity Check Index; OGTT, oral glucose tolerance test; TC, total cholesterol; HDL, high-density lipoproteins, LDL, low-density lipoproteins; TG, triglycerides; IMAT, intra- and intermuscular adipose tissue; ${ }^{*} p<0.05$. ${ }^{a}$ Echogenicity obtained from the rectus femoris of the dominant limb and measured via grayscale histogram analysis. ${ }^{b}$ IMAT and subcutaneous fat values derived from computed tomography attenuation at the mid-thigh of the dominant limb. ${ }^{c}$ Log transformed data used in the analysis. ${ }^{d}$ Total body fat estimated using

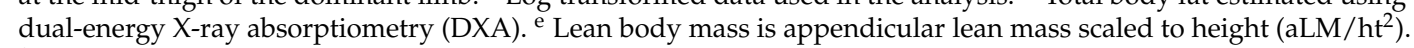

${ }_{\mathrm{f}}^{\mathrm{f}}$ Two-hour postprandial glucose values.

\subsection{Surrogate Measures of Muscle Quality, Body Composition, and Physical Performance}

Surrogate measures of muscle quality and LBM were generally associated with muscle strength. Echogenicity was the only outcome measure to be significantly associated with both absolute strength and strength values adjusted for body size. IMAT was only associated with adjusted strength values for hand grip and the knee extensors $\left(180^{\circ} / \mathrm{s}\right)$, whereas LBM was only associated with absolute strength values for grip and the knee extension at both movement velocities $\left(60^{\circ} / \mathrm{s}\right.$ and $\left.180^{\circ} / \mathrm{s}\right)$. None of the outcome measures regarding muscle tissue composition and body composition were significantly associated with customary or fast gait speed $(p>0.05)$. The relationships among surrogate measures of muscle quality, body composition estimates, and muscle strength are presented in Table 4 . 
Table 4. Associations between measures of muscle quality, physical performance and mobility.

\begin{tabular}{|c|c|c|c|c|c|c|c|}
\hline & & Grip & $\begin{array}{l}\text { Adj. } \\
\text { Grip }\end{array}$ & $\begin{array}{c}60 \% / \mathrm{s} \\
\text { Knee Ext. }\end{array}$ & $\begin{array}{l}\text { Adj. } 60 \% / s \\
\text { Knee Ext. }\end{array}$ & $\begin{array}{c}180^{\circ} / \mathrm{s} \\
\text { Knee Ext. }\end{array}$ & $\begin{array}{l}\text { Adj. } 180^{\circ} / \mathrm{s} \\
\text { Knee Ext. }\end{array}$ \\
\hline \multirow[t]{2}{*}{ Echogenicity $^{a}$} & $r$ & -0.41 & -0.50 & -0.38 & -0.47 & -0.41 & -0.49 \\
\hline & $p$-value & $0.026^{*}$ & $0.005 *$ & 0.038 * & 0.008 * & $0.025^{*}$ & $0.006^{*}$ \\
\hline \multirow[t]{2}{*}{ IMAT $^{\text {b }}$} & $r$ & -0.13 & -0.45 & -0.14 & -0.34 & -0.21 & -0.40 \\
\hline & $p$-value & 0.496 & $0.013 *$ & 0.476 & 0.069 & 0.275 & $0.029 *$ \\
\hline \multirow[t]{2}{*}{ Subcutaneous fat ${ }^{b}$} & $r$ & 0.12 & -0.16 & 0.14 & -0.02 & 0.06 & -0.10 \\
\hline & p-value & 0.519 & 0.388 & 0.451 & 0.909 & 0.760 & 0.612 \\
\hline \multirow[t]{2}{*}{ Total body fat ${ }^{c}$} & $r$ & 0.05 & -0.31 & 0.20 & -0.02 & 0.12 & -0.07 \\
\hline & p-value & 0.809 & 0.091 & 0.285 & 0.921 & 0.527 & 0.709 \\
\hline \multirow[t]{2}{*}{ Lean body mass ${ }^{d}$} & $r$ & 0.50 & 0.00 & 0.53 & 0.24 & 0.49 & 0.21 \\
\hline & p-value & $0.005^{*}$ & 0.992 & $0.002 *$ & 0.198 & $0.006^{*}$ & 0.274 \\
\hline
\end{tabular}

\footnotetext{
${ }^{1}$ All strength values reported for the dominant limb with the adjusted values scaled for body weight; ${ }^{*} p<0.05$.

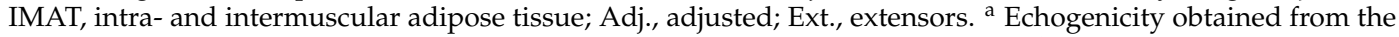
rectus femoris of the dominant limb and measured via grayscale histogram analysis. ${ }^{\mathrm{b}}$ IMAT and subcutaneous fat values derived from computed tomography attenuation at the mid-thigh of the dominant limb; log transformed data used in the analysis. ${ }^{c}$ Total body fat estimated using dual-energy X-ray absorptiometry (DXA). ${ }^{\mathrm{d}}$ Lean body mass is appendicular lean mass scaled to height $\left(\mathrm{aLM} / \mathrm{ht}^{2}\right)$.
}

\subsection{Surrogate Measures of Muscle Quality as Discriminators of Physical Performance}

We examined the ability of echogenicity and IMAT tertile values to discriminate among individuals with relatively lower and higher strength values. Significant differences in all absolute and adjusted strength values ( $p=0.016-0.026)$ were observed between participants in the first and third tertiles defined by echogenicity values. Additionally, adjusted peak hand grip force (mean difference, MD: $0.10,95 \%$ CI $(0.03-0.18), p=0.016)$ and adjusted peak knee extensor torque at $180^{\circ} / \mathrm{s}$ (MD: 0.11 , $95 \%$ CI (0.01-0.22), $p=0.040)$ significantly differed between participants in the first and third tertiles defined by IMAT values. Tertiles determined by IMAT or echogenicity did not discriminate among individuals on gait performance $(p>0.05)$ with the exception of fast gait speeds between participants with echogenicity values in the first and third tertiles (MD: $0.45 \mathrm{~m} / \mathrm{s}, 95 \% \mathrm{CI}(0.09-0.80 \mathrm{~m} / \mathrm{s}), p=0.017$ ). The comparison of mean muscle strength values based on the first and third tertile of echogenicity and IMAT are provided in Table 5.

Table 5. Differences in muscle strength based on the first and third tertiles of rectus femoris echogenicity and mid-thigh intra- and intermuscular adipose tissue estimates.

\begin{tabular}{|c|c|c|c|c|c|c|c|}
\hline & & \multicolumn{2}{|c|}{ Peak Grip Force } & \multicolumn{4}{|c|}{ Peak Knee Extensor Torque } \\
\hline & & $0 \% / \mathrm{s}(\mathrm{kg})$ & Adj. $0 \% / \mathrm{s}$ & $60^{\circ} / \mathrm{s}(\mathrm{Nm})$ & Adj. $60 \% / \mathrm{s}$ & $180 \% / \mathrm{s}(\mathrm{Nm})$ & Adj. $180^{\circ} / \mathrm{s}$ \\
\hline \multicolumn{8}{|c|}{$\begin{array}{l}\text { IMAT: } 1 \text { st and 3rd } \\
\text { tertiles }(d f=19)\end{array}$} \\
\hline$<15.7 \%$ & Mean \pm SD & $40.3 \pm 4.8$ & $0.54 \pm 0.07$ & $194.2 \pm 53.9$ & $0.61 \pm 0.14$ & $129.7 \pm 48.4$ & $0.40 \pm 0.12$ \\
\hline \multirow[t]{5}{*}{$\geq 20.0 \%$} & & $36.6 \pm 9.9$ & $0.44 \pm 0.10$ & $166.3 \pm 61.4$ & $0.49 \pm 0.16$ & $99.2 \pm 40.3$ & $0.29 \pm 0.11$ \\
\hline & MD 95\% CI & $-3.4-10.6$ & $0.02-0.18$ & $-24.7-80.6$ & $0.01-0.26$ & $-10.5-71.36$ & $0.01-0.22$ \\
\hline & SE & 3.4 & 0.04 & 25.2 & 0.07 & 19.6 & 0.05 \\
\hline & $t$ & 1.09 & 2.63 & 1.11 & 1.90 & 1.56 & 2.21 \\
\hline & $p$-value & 0.290 & $0.016^{*}$ & 0.281 & 0.076 & 0.136 & $0.040 *$ \\
\hline \multicolumn{8}{|c|}{$\begin{array}{c}\text { Echo: } 1 \text { st and 3rd } \\
\text { tertiles }(d f=18)\end{array}$} \\
\hline$<28.77$ & Mean \pm SD & $45.4 \pm 7.0$ & $0.55 \pm 0.08$ & $224.7 \pm 56.1$ & $0.64 \pm 0.07$ & $153.3 \pm 53.0$ & $0.43 \pm 0.11$ \\
\hline \multirow[t]{5}{*}{$\geq 34.54$} & & $36.4 \pm 8.2$ & $0.46 \pm 0.09$ & $153.3 \pm 59.0$ & $0.47 \pm 0.18$ & $98.7 \pm 34.0$ & $0.31 \pm 0.11$ \\
\hline & MD 95\% CI & $1.9-16.2$ & $0.01-0.17$ & $17.3-125.4$ & $0.04-0.32$ & 7.2-92.0 & $0.02-0.22$ \\
\hline & SE & 3.4 & 0.04 & 25.7 & 0.06 & 20.2 & 0.05 \\
\hline & $t$ & 2.64 & 2.43 & 2.77 & 2.94 & 2.46 & 2.50 \\
\hline & $p$-value & $0.016^{*}$ & $0.026^{*}$ & $0.013^{*}$ & $0.012 *$ & 0.024 * & $0.022 *$ \\
\hline
\end{tabular}

${ }^{1}$ All strength values reported for the dominant limb with the adjusted values scaled for body weight; ${ }^{*} p<0.05$. IMAT, intra- and intermuscular adipose tissue; Echo, echogenicity; Adj., adjusted; Ext., extensors. ${ }^{a}$ Echogenicity obtained from the rectus femoris of the dominant limb and measured via grayscale histogram analysis. ${ }^{\mathrm{b}}$ IMAT values derived from computed tomography attenuation at the mid-thigh of the dominant limb; log transformed data used in the analysis. 


\section{Discussion}

The goal of this study was to examine the construct validity of muscle echogenicity as a surrogate measure of muscle quality in a sample of older, predominantly African American men. We reported the association between rectus femoris echogenicity GSL values and mid-thigh CSA IMAT values obtained from CT imaging ( $r=0.73, p<0.001$; Figure 1$)$. Both IMAT and echogenicity exhibited significant relationships with adjusted hand grip and knee extensor strength $\left(180^{\circ} / \mathrm{s}\right)$, two-hour postprandial glucose values, and HDL values. The findings presented in this report support the construct validity of rectus femoris echogenicity as a surrogate measure of muscle quality and extend previously published data concerning the impact of excessive IMAT on muscle performance.
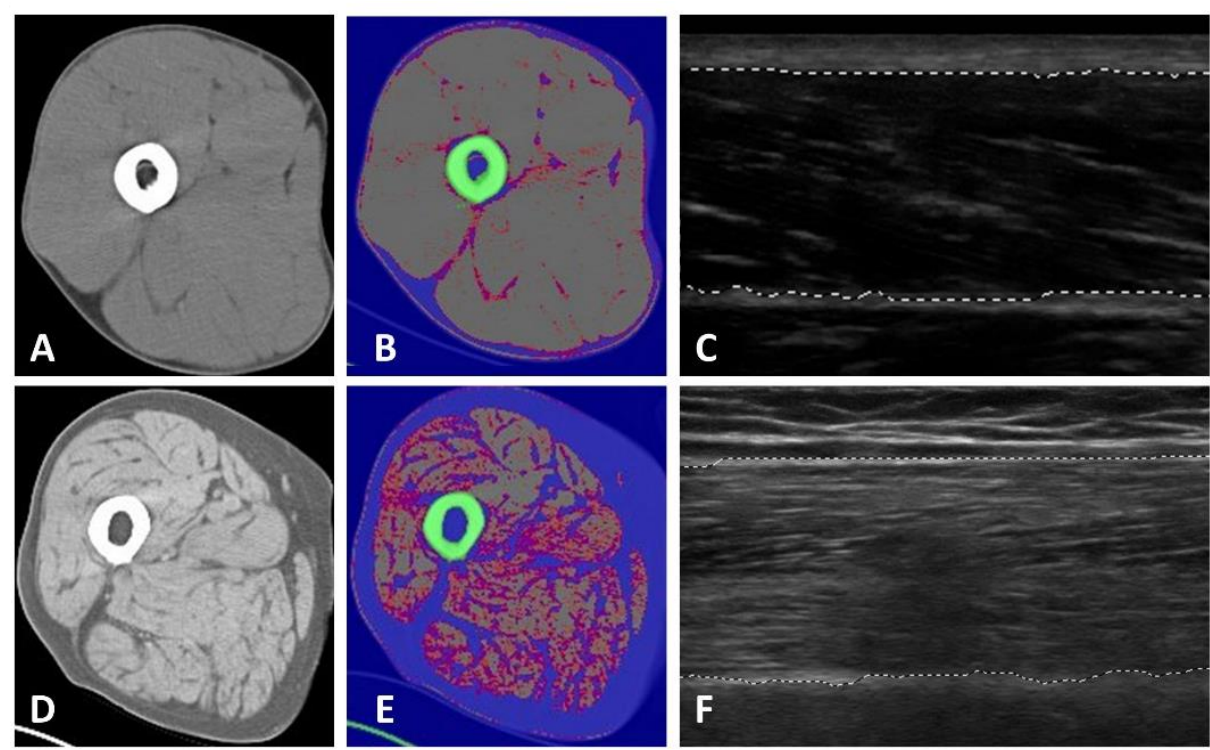

Figure 1. Exemplar ultrasound images of the rectus femoris and axial computed tomography CT images of the mid-thigh in two study participants. Mean grayscale measures of echogenicity at the rectus femoris of the dominant leg were derived from longitudinal ultrasound images and axial CT scans were obtained from the same anatomical plane at the mid-thigh. The images featured in Panel (A-C) depict a study participant with 15\% cross-sectional fat mass and $7 \%$ intra- and intermuscular adipose tissue (IMAT). In contrast, the images in Panel (D-F) show a study participant with $66 \%$ cross-sectional fat mass and $40 \%$ IMAT (Hounsfield units: -190 to -30 for adipose tissue, 0 to +30 for low density muscle, and +31 to +100 for normal density muscle tissue).

\subsection{Surrogate Measures of Muscle Quality Are Associated with Strength and Physical Performance}

Age-related changes in muscle tissue composition are associated with diminished strength and poor longitudinal health outcomes [23,30]. Foundational work concerning the link between muscle quality and physical performance was established in older adults based on CT muscle attenuation values [29,54], and later corroborated using ultrasound muscle echogenicity values [21,55]. Quadriceps muscle echogenicity has been significantly associated with peak isometric knee extensor strength even when adjusting for age, muscle size, or subcutaneous fat [20,21]. Moreover, muscle echogenicity measures of the anterior thigh musculature have been reported to be inversely related to strength and gait speed, and may discriminate between older women who are able or unable to ambulate independently [56]. Our reported findings regarding the moderate independent association of rectus femoris echogenicity with peak knee extensor torque is consistent with the findings of Fukumoto et al. [20] and Watanabe et al. [21]. Furthermore, we observed that echogenicity of the rectus femoris was consistently associated with all upper and lower extremity strength outcomes with and without adjustments for body size. In contrast, LBM was moderately related to only measures of strength unadjusted for body size. The significant association between rectus femoris echogenicity 
and grip strength in the current sample of older men supports our earlier reported observation in a sample of younger and older community-dwelling women [19].

Regarding functional performance, Visser and associates [29] have reported that a model of knee extensor muscle strength and mid-thigh IMAT, but not muscle cross-sectional area, predicted self-reported mobility limitations in older adults. High levels of IMAT (i.e., myosteatosis) have also been significantly associated with impaired lower extremity function in large cohorts of community dwelling adults and may help explain why decreases in LBM are not linearly related to declines in physical performance [21,54]. Furthermore, quadriceps echogenicity has been shown to be among the strongest independent variables in predictive models of timed sit-to-stand performance in a sample of sedentary older men [57]. In the current study, we observed significant differences in mobility in study participants during the fast gait testing condition when considering those in the first and third tertiles of echogenicity values, but not IMAT values. While muscle tissue composition estimates appear to be independently associated with muscle performance, it is likely that the relationship of muscle morphology with functional performance varies based on sample characteristics, selection of the functional test, and the method of tissue analysis employed [58-60].

\subsection{The Comparative Use of Ultrasound, Computed Tomography (CT), and Magnetic Resonance Imaging (MRI) for Muscle Tissue Composition Estimates}

The findings of this report build upon previous validation studies regarding the relationship of diagnostic ultrasound muscle morphology measures with CT estimates of tissue composition [61]. This early work was centered on the comparative use of: backscattered radio frequency signals and CT muscle density estimates; compound ultrasound image acquisition supplemented by multiple photographs to obtain muscle morphology data; use of a four-point subjective scale to assess intramuscular echogenicity $[13,62,63]$. Sipilä and Suominen's $[13,63]$ work involving older women athletes $(73.7 \pm 5.6$ years old) from Finland showed that anterior mid-thigh echogenicity scores were inversely associated with the mean quadriceps HU values $(r=-0.351, p<0.05)$. We observed a stronger relationship between muscle echogenicity and CT estimates of muscle composition in our study sample than did Sipilä and Suominen, possibly because of differences in lower extremity IMAT based on sample characteristics such as sex, age, and racial/ethnic group [48,64,65]. Although the older, predominantly African American sample of men evaluated in our study differs greatly from the older Finnish women included in the Sipilä and Suominen study [13], other important study differences that may have contributed to differences in findings include the ROI examined within the anterior thigh musculature, echogenicity measurement methods, and the muscle mass HU cutoff values used to denote normal density muscle tissue. The HU cutoff values used in the current study were those established by Goodpaster et al. [35] $(+31$ to $+100 \mathrm{HU})$, whereas the cutoff values used by Sipilä and Suominen [13] $(0$ to $+150 \mathrm{HU})$ were determined via their pilot work and informed by studies that preceded their investigation [66].

Recent studies have served to validate the use of muscle echogenicity to assess muscle tissue composition using reference values from MRI $[17,67]$. Young et al. [67] evaluated echogenicity and MRI estimates of IMAT in four lower extremity muscle groups in a sample of adult men $(n=14$; age: $27.9 \pm 14.9$ years) and women ( $n=17$; age: $21.9 \pm 2.5$ years). The rectus femoris was the common muscle group featured in both this report and the study conducted by Young et al. [66]. The echogenicity of the rectus femoris was significantly associated with IMAT estimates derived from the determined voxel intensity obtained from the same region using T1-weighted MRI images. However, the approach used in the current report was to examine the IMAT for the entire musculature of the mid-thigh using axial CT scans. The proportion of IMAT identified at the mid-thigh CSA was a median value of $17.1 \%$ (IQR: $14.18 \%, 22.56 \%$ ) for our sample. The proportions of lower extremity IMAT reported in this work and by Young et al. [66] are comparable, with the modestly higher values reported by our group being influenced by the reference imaging modality, older study participants, and use of mid-thigh CSA tissue segmentation inclusive of all muscle groups. 
Additionally, the strength of association between echogenicity and IMAT via MRI is comparatively higher in the results reported by Young et al. [67] given their use of corresponding ROIs for individual lower extremity muscle groups. In contrast, a key objective of the current work was to understand whether the echogenicity detected within the limited field of view provided by the rectus femoris scan could broadly reflect mid-thigh CSA IMAT based on CT imaging. While there are important methodological differences between our investigation and the aforementioned validation studies using $\mathrm{CT}$ and MRI, they all collectively support the use of muscle tissue echogenicity as a viable surrogate measure of muscle quality.

\subsection{Quantitative Ultrasound Muscle Measures Are Linked to Tissue Properties and Health Outcomes}

Other investigators have recently reported compelling links between muscle tissue properties and echogenicity. Akima et al. [17] recently provided evidence suggesting that lower extremity echogenicity values largely reflect extramyocellular lipids in a sample of young ( $n=15$; age: $20.9 \pm 0.3$ years) and old adults ( $n=15$; age: $70.7 \pm 3.8$ years) based on ${ }^{1} \mathrm{H}$ MRS analysis. Vastus lateralis and biceps femoris echogenicity exhibited moderate associations with ${ }^{1} \mathrm{H}$ MRS estimates of extramyocellular lipids ( $r=0.49, p<0.01$, and $r=0.65, p<0.001$, respectively), but the associations with intramyocellular lipids were non-significant. Using a histochemical approach to characterize muscle tissue composition, Choi et al. [68] obtained vastus lateralis biopsy samples from older participants, and analyzed muscle fibers for intramyocellular lipids in a subset of 10 participants (normal weight, $n=5$; obese, $n=5$ ), with the obese subgroup displaying 2.4-fold more intramyocellular lipids than in the normal weight subgroup [68]. The standard deviation (SD) of the quadriceps echogenicity values was positively associated with the proportion of intramyocellular lipids $(r=0.75, p=0.02)$ and negatively associated with single-fiber specific force $(r=-0.74, p=0.02)$. In reviewing the discordant findings of Akima et al. [17] and Choi et al. [68], it should be noted that extramyocellular lipid spectroscopy signals are position dependent and their discrete distribution in proximity to muscle fasciculi will result in varied signal amplitudes depending on location, whereas intramyocellular lipid spectroscopy signals are relatively impervious to minor voxel translocations [69,70]. Moreover, the significant relationship between echogenicity and intramyocellular lipids reported by Choi et al. [68] may be partially explained by their inclusion of obese participants and their use of grayscale histogram dispersion data to characterize the quadriceps ROI. In considering the findings of this report and the aforementioned studies of Akima and Choi, surrogate measures of muscle quality appear to have utility in characterizing muscle morphology and performance in clinical settings.

The relationship of muscle tissue composition with biomarkers of cardiometabolic health is an active area of study [24,71], but is less well studied using sonographic methods in comparison to CT methods. Findings from the Framingham Heart Study cohort $(n=2945)$ involving older men (age: $49.6 \pm 10.7$ years) and women (age: $52.0 \pm 9.8$ years) suggested that CT estimates of IMAT are significantly associated with certain metabolic measures. For example, both HDL $(p<0.0001)$ and triglycerides $(p<0.001)$ were associated with $\mathrm{CT}$ attenuation of the paraspinous muscles after adjusting for BMI and visceral fat in men [71]. In the current report, muscle echogenicity and CT estimates of IMAT were both significantly associated with HDL and postprandial glucose values results in our sample of older men. These relationships were similar when controlling for covariates of age and body fat percentage in a multiple linear regression model for predicting postprandial glucose values. However, the strength of the relationship between echogenicity and HDL was diminished when controlling for both covariates. This result may reflect the limited field of view for the rectus femoris echogenicity measures in comparison to the full mid-thigh CSA IMAT estimate derived from CT attenuation values. Nevertheless, the significant relationship between echogenicity and the postprandial glucose values $(r=0.43, p=0.018)$ in our report is strengthened by the prior observation that extramyocellular lipids are negatively associated with insulin sensitivity $(r=-0.53, p<0.05)$ even in very young study participants [72]. Estimates of muscle tissue composition using mid-thigh CT attenuation may exhibit an independent association with insulin resistance [73], but this relationship 
is modified by participant sex and racial/ethnic background [74]. In considering the participant demographics of our sample, it should be noted that higher estimates of IMAT have been reported in lean diabetic versus non diabetic older men of African ancestry $(p<0.01)[48,74]$. These significant differences in IMAT were retained even after adjusting for age, stature, total muscle area, and total fat [48]. These collective findings suggest that surrogate measures of muscle quality may inform the clinical management of individuals with metabolic disorders and age-related muscle dysfunction.

\subsection{Limitations and Future Work}

This work has several important limitations that affect the interpretation of the findings. The use of quantitative ultrasound to characterize muscle morphology was limited to echogenicity expressed as grayscale values. However, the findings of this report do not suggest that muscle morphology features besides echogenicity are not important contributors to physical performance in older adults $[59,75]$. Rather, the findings support the inclusion of muscle composition estimates via echogenicity among the clinical markers used to assess and monitor muscle health in aging adults [11,74]. Additionally, the ability of echogenicity to estimate myosteatosis is likely limited to extramyocellular lipids. Intramyocellular lipids have a stronger inverse relationship with insulin sensitivity than extramyocellular lipids, even after controlling for percent total body fat and abdominal subcutaneous fat [72]. Consequently, the findings in this report may underestimate the relationship between muscle composition and metabolic status. Furthermore, the association of metabolic status with IMAT, body composition, and echogenicity may differ from our findings in older adults with metabolic syndrome.

A single scanning site was used to obtain echogenicity measures in this work. While the mid-thigh is a body region frequently included in muscle composition research $[27,28,54]$, the association between echogenicity and metabolic status may vary with different scanning locations. Importantly, the study participants were ambulatory patients enrolled at an urban U.S. VA medical center and may differ from patients in hospital catchment areas that service rural communities and other geographical locations. Additionally, the findings in this report reflect a sample of predominantly African American participants. Nevertheless, similar relationships between estimates of muscle composition with muscle performance and cardiometabolic health have been observed in diverse patient populations $[19,21,71,72]$. However, given the impact of age, sex, and nutritional status on total body adiposity and muscle echogenicity, larger studies with appropriate group assignment are needed to account for these factors. The interpretation of data concerning the relationship between muscle composition and performance-based measures would also benefit from a larger study sample. While this work included pragmatic laboratory measures of metabolic status, estimates of metabolic function and associated health-risks would have been better characterized by additional tests and measures. These measures include the waist-to-hip ratio, homeostatic model assessment, glucose clamp technique, or alternate forms of dynamic indices involving postprandial insulin measures.

\section{Conclusions}

It is well known that adverse changes in muscle quality-based on estimates of muscle tissue composition-are associated with diminished strength and poor longitudinal health outcomes $[11,23,30,54]$. Regrettably, the evidence for estimating muscle composition to assess and monitor muscle health has not been successfully integrated into clinical practice. Barriers to integrating contemporary evidence-based approaches to assessing muscle tissue composition are linked to the radiation exposure concerns associated with CT scanning, the limitations of DXA, and cost/access issues regarding MRI [9]. Quantitative ultrasound may provide a safe, low cost, portable, and relatively accessible imaging alternative for the estimation of muscle tissue composition. In this report, construct validity of ultrasound was examined based on the association of rectus femoris echogenicity with mid-thigh CT scan estimates of IMAT, basic metabolic parameters via blood sample analysis, muscle strength, and mobility status. Our findings in a sample of older, predominantly African American men 
indicate that rectus femoris echogenicity is strongly associated with CT scan estimates of IMAT at the mid-thigh. Moreover, our data suggest that echogenicity and CT scan estimates of IMAT are similarly associated with postprandial glucose values and HDL values, as well as hand grip strength, and knee extension $\left(180^{\circ} / \mathrm{s}\right)$ strength values adjusted for body size. Given the similar associations of mid-thigh echogenicity and CT scan estimates of IMAT with physical performance and metabolic parameters in our older male participants, echogenicity should be further considered as a surrogate measure of muscle quality.

Author Contributions: Conceptualization, M.H.L.; Methodology, M.H.L., M.R.B., N.A.A., C.I. and B.A.; Software, M.H.L. and F.L.; Validation, M.H.L., N.A.A., M.R.B. and J.Z.; Formal Analysis, M.H.L.; Investigation, M.H.L., B.A., N.A.A., B.A.S., C.A.K. and S.H.Z.; Resources, M.R.B., F.L., N.A.A. and M.H.L.; Data Curation, M.H.L., B.A., F.L. and J.Z.; Writing-Original Draft Preparation, M.H.L.; Writing-Review and Editing, M.H.L., M.R.B., B.A.S., N.A.A., C.I., F.L., J.Z., B.A., C.A.K. and S.H.Z.; Visualization, M.H.L.; Supervision, M.H.L., M.R.B., F.L. and N.A.A.; Project Administration, M.H.L. and M.R.B.; Funding Acquisition, M.H.L. and M.R.B.

Funding: This work was supported by the VA Capitol Health Care Network Pilot Grant Program (VISN 5; VA Station: 688) and the VA Historically Black Colleges and Universities Research Scientist Training Program (VA-HBCU RSTP) from the Rehabilitation R\&D Service at the VA Office of Research and Development (1IK2RX001854). Additional project support was provided by the National Center for Advancing Translational Sciences, National Institutes of Health (NCATS/NIH), through the Clinical and Translational Science Awards Program (CTSA UL1TR000101).

Acknowledgments: We thank the following individuals and clinical service groups for their contributions to this investigation: Leela Chacko, Joel Scholten and Heather Malecki of the DC VAMC Physical Medicine and Rehabilitation Service for the provision of equipment and patient examination space; Elizabeth Cobbs of the DC VAMC Geriatrics and Extended Care Service for the allocation of personnel; Brian Garra, formerly of the DC VAMC Department of Radiology, for providing bioimaging consultation; Jack H. Lichy of the DC VAMC Clinical Pathology Laboratory for the provision of clinical services in support of this work.

Conflicts of Interest: The authors declare no conflict of interest. The funding agencies had no role in the design of the study; in the collection, analyses, or interpretation of data; in the writing of the manuscript, and in the decision to publish the results. Any opinions or recommendations expressed in this publication are those of the authors and do not necessarily reflect the view of the U.S. Department of Veterans Affairs or the U.S. Department of Health and Human Services.

\section{References}

1. Heard, R.S.M.; Ramsay, G.; Hildebrand, D.R. Sarcopaenia in surgical populations: A review. Surgeon 2017, 15, 366-371. [CrossRef] [PubMed]

2. Gariballa, S.; Alessa, A. Sarcopenia: Prevalence and prognostic significance in hospitalized patients. Clin. Nutr. 2013, 32, 772-776. [CrossRef] [PubMed]

3. Goodpaster, B.H.; Carlson, C.L.; Visser, M.; Kelley, D.E.; Scherzinger, A.; Harris, T.B.; Stamm, E.; Newman, A.B. Attenuation of skeletal muscle and strength in the elderly: The Health ABC Study. J. Appl. Physiol. 2001, 90, 2157-2165. [CrossRef] [PubMed]

4. Goodpaster, B.H.; Park, S.W.; Harris, T.B.; Kritchevsky, S.B.; Nevitt, M.; Schwartz, A.V.; Simonsick, E.M.; Tylavsky, F.A.; Visser, M.; Newman, A.B. The loss of skeletal muscle strength, mass, and quality in older adults: The Health, Aging and Body Composition study. J. Gerontol. A Biol. Sci. Med. Sci. 2006, 61, 1059-1064. [CrossRef] [PubMed]

5. Heymsfield, S.B.; Gonzalez, M.C.; Lu, J.; Jia, G.; Zheng, J. Skeletal muscle mass and quality: Evolution of modern measurement concepts in the context of sarcopenia. Proc. Nutr. Soc. 2015, 74, 355-366. [CrossRef] [PubMed]

6. Teigen, L.M.; Kuchnia, A.J.; Mourtzakis, M.; Earthman, C.P. The use of technology for estimating body composition: Strengths and weaknesses of common modalities in a clinical setting. Nutr. Clin. Pract. 2017, 32, 20-29. [CrossRef] [PubMed]

7. Sanada, K.; Kearns, C.F.; Midorikawa, T.; Abe, T. Prediction and validation of total and regional skeletal muscle mass by ultrasound in Japanese adults. Eur. J. Appl. Physiol. 2006, 96, 24-31. [CrossRef] [PubMed]

8. Abe, T.; Kondo, M.; Kawakami, Y.; Fukunaga, T. Prediction equations for body composition of Japanese adults by B-mode ultrasound. Am. J. Hum. Biol. 1994, 6, 161-170. [CrossRef] [PubMed] 
9. Harris-Love, M.O.; Monfaredi, R.; Ismail, C.; Blackman, M.R.; Cleary, K. Quantitative ultrasound: Measurement considerations for the assessment of muscular dystrophy and sarcopenia. Front. Aging Neurosci. 2014, 6, 1-4. [CrossRef] [PubMed]

10. Pillen, S.; van Alfen, N. Skeletal muscle ultrasound. Neurol. Res. 2011, 33, 1016-1024. [CrossRef] [PubMed]

11. Correa-de-Araujo, R.; Harris-Love, M.O.; Miljkovic, I.; Fragala, M.S.; Anthony, B.W.; Manini, T.M. The need for standardized assessment of muscle quality in skeletal muscle function deficit and other aging-related muscle dysfunctions: A symposium report. Front. Physiol. 2017, 8, 1-19. [CrossRef] [PubMed]

12. Iftekharuddin, K.M.; Awwal, A.A.S. Field Guide to Image Processing; SPIE Field Guides; SPIE Press: Bellingham, WA, USA, 2012; ISBN 978-0-8194-9021-6.

13. Sipilä, S.; Suominen, H. Muscle ultrasonography and computed tomography in elderly trained and untrained women. Muscle Nerve 1993, 16, 294-300. [CrossRef] [PubMed]

14. Pillen, S.; Verrips, A.; van Alfen, N.; Arts, I.M.P.; Sie, L.T.L.; Zwarts, M.J. Quantitative skeletal muscle ultrasound: Diagnostic value in childhood neuromuscular disease. Neuromuscul. Disord. 2007, 17, 509-516. [CrossRef] [PubMed]

15. Hu, C.-F.; Chen, C.P.-C.; Tsai, W.-C.; Hu, L.-L.; Hsu, C.-C.; Tseng, S.-T.; Shau, Y.-W. Quantification of skeletal muscle fibrosis at different healing stages using sonography: A morphologic and histologic study in an animal model. J. Ultrasound Med. 2012, 31, 43-48. [CrossRef] [PubMed]

16. Reimers, K.; Reimers, C.D.; Wagner, S.; Paetzke, I.; Pongratz, D.E. Skeletal muscle sonography: A correlative study of echogenicity and morphology. J. Ultrasound Med. 1993, 12, 73-77. [CrossRef] [PubMed]

17. Akima, H.; Hioki, M.; Yoshiko, A.; Koike, T.; Sakakibara, H.; Takahashi, H.; Oshida, Y. Intramuscular adipose tissue determined by T1-weighted MRI at 3T primarily reflects extramyocellular lipids. Magn. Reson. Imaging 2016, 34, 397-403. [CrossRef] [PubMed]

18. Fukumoto, Y.; Tateuchi, H.; Ikezoe, T.; Tsukagoshi, R.; Akiyama, H.; So, K.; Kuroda, Y.; Ichihashi, N. Effects of high-velocity resistance training on muscle function, muscle properties, and physical performance in individuals with hip osteoarthritis: A randomized controlled trial. Clin. Rehabil. 2014, 28, 48-58. [CrossRef] [PubMed]

19. Ismail, C.; Zabal, J.; Hernandez, H.J.; Woletz, P.; Manning, H.; Teixeira, C.; DiPietro, L.; Blackman, M.R.; Harris-Love, M. Diagnostic ultrasound estimates of muscle mass and muscle quality discriminate between women with and without sarcopenia. Front. Physiol. 2015, 6, 1-10. [CrossRef] [PubMed]

20. Fukumoto, Y.; Ikezoe, T.; Yamada, Y.; Tsukagoshi, R.; Nakamura, M.; Mori, N.; Kimura, M.; Ichihashi, N. Skeletal muscle quality assessed from echo intensity is associated with muscle strength of middle-aged and elderly persons. Eur. J. Appl. Physiol. 2012, 112, 1519-1525. [CrossRef] [PubMed]

21. Watanabe, Y.; Yamada, Y.; Fukumoto, Y.; Ishihara, T.; Yokoyama, K.; Yoshida, T.; Miyake, M.; Yamagata, E.; Kimura, M. Echo intensity obtained from ultrasonography images reflecting muscle strength in elderly men. Clin. Interv. Aging 2013, 8, 993-998. [CrossRef] [PubMed]

22. Hairi, N.N.; Cumming, R.G.; Naganathan, V.; Handelsman, D.J.; Le Couteur, D.G.; Creasey, H.; Waite, L.M.; Seibel, M.J.; Sambrook, P.N. Loss of muscle strength, mass (sarcopenia), and quality (specific force) and its relationship with functional limitation and physical disability: The Concord Health and Ageing in Men Project. J. Am. Geriatr. Soc. 2010, 58, 2055-2062. [CrossRef] [PubMed]

23. Cawthon, P.M.; Fox, K.M.; Gandra, S.R.; Delmonico, M.J.; Chiou, C.-F.; Anthony, M.S.; Sewall, A.; Goodpaster, B.; Satterfield, S.; Cummings, S.R.; et al. Do muscle mass, muscle density, strength, and physical function similarly influence risk of hospitalization in older adults? J. Am. Geriatr. Soc. 2009, 57, 1411-1419. [CrossRef] [PubMed]

24. Miljkovic, I.; Kuipers, A.L.; Cauley, J.A.; Prasad, T.; Lee, C.G.; Ensrud, K.E.; Cawthon, P.M.; Hoffman, A.R.; Dam, T.-T.; Gordon, C.L.; et al. Greater skeletal muscle fat infiltration is associated with higher all-cause and cardiovascular mortality in older men. J. Gerontol. A. Biol. Sci. Med. Sci. 2015, 70, 1133-1140. [CrossRef] [PubMed]

25. Buckinx, F.; Landi, F.; Cesari, M.; Fielding, R.A.; Visser, M.; Engelke, K.; Maggi, S.; Dennison, E.; Al-Daghri, N.M.; Allepaerts, S.; et al. Pitfalls in the measurement of muscle mass: A need for a reference standard. J. Cachexia Sarcopenia Muscle 2018, 9, 269-278. [CrossRef] [PubMed]

26. Cooper, C.; Fielding, R.; Visser, M.; Loon, L.J.; Rolland, Y.; Orwoll, E.; Reid, K.; Boonen, S.; Dere, W.; Epstein, S.; et al. Tools in the assessment of sarcopenia. Calcif. Tissue Int. 2013, 93, 201-210. [CrossRef] [PubMed] 
27. Harris-Love, M.O.; Seamon, B.A.; Teixeira, C.; Ismail, C. Ultrasound estimates of muscle quality in older adults: Reliability and comparison of Photoshop and ImageJ for the grayscale analysis of muscle echogenicity. PeerJ 2016, 4, 1-23. [CrossRef] [PubMed]

28. Miller, R.R.; Eastlack, M.; Hicks, G.E.; Alley, D.E.; Shardell, M.D.; Orwig, D.L.; Goodpaster, B.H.; Chomentowski, P.J.; Hawkes, W.G.; Hochberg, M.C.; et al. Asymmetry in CT scan measures of thigh muscle 2 months after hip fracture: The Baltimore Hip Studies. J. Gerontol. A Biol. Sci. Med. Sci. 2015, 70, 1276-1280. [CrossRef] [PubMed]

29. Visser, M.; Goodpaster, B.H.; Kritchevsky, S.B.; Newman, A.B.; Nevitt, M.; Rubin, S.M.; Simonsick, E.M.; Harris, T.B. Muscle mass, muscle strength, and muscle fat infiltration as predictors of incident mobility limitations in well-functioning older persons. J. Gerontol. A Biol. Sci. Med. Sci. 2005, 60, 324-333. [CrossRef] [PubMed]

30. Lang, T.; Cauley, J.A.; Tylavsky, F.; Bauer, D.; Cummings, S.; Harris, T.B. Computed tomographic measurements of thigh muscle cross-sectional area and attenuation coefficient predict hip fracture: The Health, Aging, and Body Composition Study. J. Bone Miner. Res. 2010, 25, 513-519. [CrossRef] [PubMed]

31. Alley, D.E.; Shardell, M.D.; Peters, K.W.; McLean, R.R.; Dam, T.-T.L.; Kenny, A.M.; Fragala, M.S.; Harris, T.B.; Kiel, D.P.; Guralnik, J.M.; et al. Grip strength cutpoints for the identification of clinically relevant weakness. J. Gerontol. A Biol. Sci. Med. Sci. 2014, 69, 559-566. [CrossRef] [PubMed]

32. Tieland, M.; Verdijk, L.B.; de Groot, L.C.P.G.M.; van Loon, L.J.C. Handgrip strength does not represent an appropriate measure to evaluate changes in muscle strength during an exercise intervention program in frail older people. Int. J. Sport Nutr. Exerc. Metab. 2015, 25, 27-36. [CrossRef] [PubMed]

33. Bijlsma, A.Y.; Meskers, C.G.M.; van Heemst, D.; Westendorp, R.G.J.; de Craen, A.J.M.; Maier, A.B. Diagnostic criteria for sarcopenia relate differently to insulin resistance. Age 2013, 35, 2367-2375. [CrossRef] [PubMed]

34. Schneider, C.A.; Rasband, W.S.; Eliceiri, K.W. NIH Image to ImageJ: 25 years of image analysis. Nat. Methods 2012, 9, 671-675. [CrossRef] [PubMed]

35. Goodpaster, B.H.; Thaete, F.L.; Kelley, D.E. Composition of skeletal muscle evaluated with computed tomography. Ann. N. Y. Acad. Sci. 2000, 904, 18-24. [CrossRef] [PubMed]

36. Jaric, S. Role of body size in the relation between muscle strength and movement performance. Exerc. Sport Sci. Rev. 2003, 31, 8-12. [CrossRef] [PubMed]

37. Jaric, S. Muscle strength testing-Use of normalisation for body size. Sports Med. 2002, 32, 615-631. [CrossRef] [PubMed]

38. Stenholm, S.; Sallinen, J.; Koster, A.; Rantanen, T.; Sainio, P.; Heliövaara, M.; Koskinen, S. Association between obesity history and hand grip strength in older adults-Exploring the roles of inflammation and insulin resistance as mediating factors. J. Gerontol. A Biol. Sci. Med. Sci. 2011, 66, 341-348. [CrossRef] [PubMed]

39. Günther, C.M.; Bürger, A.; Rickert, M.; Crispin, A.; Schulz, C.U. Grip strength in healthy Caucasian adults: Reference values. J. Hand Surg. 2008, 33, 558-565. [CrossRef] [PubMed]

40. Vermeulen, J.; Neyens, J.C.L.; Spreeuwenberg, M.D.; van Rossum, E.; Hewson, D.J.; de Witte, L.P. Measuring grip strength in older adults: Comparing the grip-ball with the Jamar dynamometer. J. Geriatr. Phys. Ther. 2015, 38, 148-153. [CrossRef] [PubMed]

41. Harris-Love, M.O. Safety and efficacy of submaximal eccentric strength training for a subject with polymyositis. Arthritis Rheum. 2005, 53, 471-474. [CrossRef] [PubMed]

42. Pincivero, D.; Lephart, S.; Karunakara, R. Reliability and precision of isokinetic strength and muscular endurance for the quadriceps and hamstrings. Int. J. Sports Med. 1997, 18, 113-117. [CrossRef] [PubMed]

43. Hartmann, A.; Knols, R.; Murer, K.; de Bruin, E.D. Reproducibility of an isokinetic strength-testing protocol of the knee and ankle in older adults. Gerontology 2009, 55, 259-268. [CrossRef] [PubMed]

44. Bohannon, R.W.; Andrews, A.W.; Thomas, M.W. Walking speed: Reference values and correlates for older adults. J. Orthop. Sports Phys. Ther. 1996, 24, 86-90. [CrossRef] [PubMed]

45. Wolf, S.L.; Catlin, P.A.; Gage, K.; Gurucharri, K.; Robertson, R.; Stephen, K. Establishing the reliability and validity of measurements of walking time using the Emory Functional Ambulation Profile. Phys. Ther. 1999, 79, 1122-1133. [PubMed]

46. Portney, L.G.; Watkins, M.P. Foundations of Clinical Research: Applications to Practice; Pearson/Prentice Hall: Upper Saddle River, NJ, USA, 2009; ISBN 978-0-13-171640-7. 
47. Field, A. Discovering Statistics Using SPSS; Sage: Los Angeles, CA, 2009; ISBN 978-1-84787-906-6.

48. Miljkovic-Gacic, I.; Gordon, C.L.; Goodpaster, B.H.; Bunker, C.H.; Patrick, A.L.; Kuller, L.H.; Wheeler, V.W.; Evans, R.W.; Zmuda, J.M. Adipose tissue infiltration in skeletal muscle: Age patterns and association with diabetes among men of African ancestry. Am. J. Clin. Nutr. 2008, 87, 1590-1595. [CrossRef] [PubMed]

49. Foster, S.L.; Cone, J.D. Validity issues in clinical assessment. Psychol. Assess. 1995, 7, 248-260. [CrossRef]

50. Harris-Love, M.O.; Adams, B.; Ismail, C.; Hernandez, H.J.; McIntosh, V.; Yang, J.; Chacko, L.; Blackman, M.R.; Garra, B.S. Ultrasound proxy measures of muscle quality are associated with strength and functional performance in older men. J. Frailty Aging 2015, 4, 55-56. [CrossRef]

51. Roseveare, D. World Congress on Osteoporosis, Osteoarthritis and Musculoskeletal Diseases (WCO-IOF-ESCEO 2018): Poster Abstracts. Osteoporos. Int. 2018, 29, 149-565. [CrossRef] [PubMed]

52. Yorke, A.M.; Curtis, A.B.; Shoemaker, M.; Vangsnes, E. Grip strength values stratified by age, gender, and chronic disease status in adults aged 50 years and older. J. Geriatr. Phys. Ther. 2015, 38, 115-121. [CrossRef] [PubMed]

53. Abellan van Kan, G.; Rolland, Y.; Andrieu, S.; Bauer, J.; Beauchet, O.; Bonnefoy, M.; Cesari, M.; Donini, L.M.; Gillette Guyonnet, S.; Inzitari, M.; et al. Gait speed at usual pace as a predictor of adverse outcomes in community-dwelling older people an International Academy on Nutrition and Aging (IANA) Task Force. J. Nutr. Health Aging 2009, 13, 881-889. [CrossRef] [PubMed]

54. Delmonico, M.J.; Harris, T.B.; Visser, M.; Park, S.W.; Conroy, M.B.; Velasquez-Mieyer, P.; Boudreau, R.; Manini, T.M.; Nevitt, M.; Newman, A.B.; et al. Health, Aging, and Body Longitudinal study of muscle strength, quality, and adipose tissue infiltration. Am. J. Clin. Nutr. 2009, 90, 1579-1585. [CrossRef] [PubMed]

55. Harris-Love, M.O.; Avila, N.A.; Adams, B.; Ismail, C.; Zaidi, S.; Kassner, C.; Liu, F.; Blackman, M.R. Ultrasound echogenicity at the rectus femoris predicts attenuation on computed tomography in the evaluation of thigh tissue composition. J. Frailty Aging 2015, 4, 55. [CrossRef]

56. Akazawa, N.; Okawa, N.; Tamura, K.; Moriyama, H. Relationships between intramuscular fat, muscle strength and gait independence in older women: A cross-sectional study. Geriatr. Gerontol. Int. 2016. [CrossRef] [PubMed]

57. Lopez, P.; Wilhelm, E.N.; Rech, A.; Minozzo, F.; Radaelli, R.; Pinto, R.S. Echo intensity independently predicts functionality in sedentary older men. Muscle Nerve 2017, 55, 9-15. [CrossRef] [PubMed]

58. Parry, S.M.; El-Ansary, D.; Cartwright, M.S.; Sarwal, A.; Berney, S.; Koopman, R.; Annoni, R.; Puthucheary, Z.; Gordon, I.R.; Morris, P.E.; et al. Ultrasonography in the intensive care setting can be used to detect changes in the quality and quantity of muscle and is related to muscle strength and function. J. Crit. Care 2015, 30, 1151.e9-1151.e14. [CrossRef] [PubMed]

59. Shaffer, N.C.; Fabbri, E.; Ferrucci, L.; Shardell, M.; Simonsick, E.M.; Studenski, S. Muscle quality, strength, and lower extremity physical performance in the Baltimore Longitudinal Study of Aging. J. Frailty Aging 2017, 6, 183-187. [CrossRef]

60. Rech, A.; Radaelli, R.; Goltz, F.R.; da Rosa, L.H.T.; Schneider, C.D.; Pinto, R.S. Echo intensity is negatively associated with functional capacity in older women. Age 2014, 36, 9708. [CrossRef] [PubMed]

61. Cady, E.B.; Gardener, J.E. Tissue Characterization of Normal and Dystrophic Muscle Using Broad-Band Backscattered, R.F. Data. In Ultrasound Interactions in Biology and Medicine; Millner, R., Rosenfeld, E., Cobet, U., Eds.; Springer: Boston, MA, USA, 1983; pp. 77-84. ISBN 978-1-4684-8386-4.

62. Cady, E.B.; Gardener, J.E.; Edwards, R.H.T. Ultrasonic tissue characterisation of skeletal muscle. Eur. J. Clin. Investig. 1983, 13, 469-473. [CrossRef]

63. Sipilä, S.; Suominen, H. Ultrasound imaging of the quadriceps muscle in elderly athletes and untrained men. Muscle Nerve 1991, 14, 527-533. [CrossRef] [PubMed]

64. Harris-Love, M.O.; Adams, B.; Hernandez, H.J.; DiPietro, L.; Blackman, M.R. Disparities in the consequences of sarcopenia: Implications for African American Veterans. Front. Physiol. 2014, 5, 250. [CrossRef] [PubMed]

65. Miljkovic, I.; Cauley, J.A.; Petit, M.A.; Ensrud, K.E.; Strotmeyer, E.; Sheu, Y.; Gordon, C.L.; Goodpaster, B.H.; Bunker, C.H.; Patrick, A.L.; et al. Osteoporotic Fractures in Men Research Group; Tobago Health Studies Research Group Greater adipose tissue infiltration in skeletal muscle among older men of African ancestry. J. Clin. Endocrinol. Metab. 2009, 94, 2735-2742. [CrossRef] [PubMed]

66. Borkan, G.A.; Hults, D.E.; Gerzof, S.G.; Robbins, A.H.; Silbert, C.K. Age changes in body composition revealed by computed tomography. J. Gerontol. 1983, 38, 673-677. [CrossRef] [PubMed] 
67. Young, H.-J.; Jenkins, N.T.; Zhao, Q.; Mccully, K.K. Measurement of intramuscular fat by muscle echo intensity. Muscle Nerve 2015, 52, 963-971. [CrossRef] [PubMed]

68. Choi, S.J.; Files, D.C.; Zhang, T.; Wang, Z.-M.; Messi, M.L.; Gregory, H.; Stone, J.; Lyles, M.F.; Dhar, S.; Marsh, A.P.; et al. Intramyocellular lipid and impaired myofiber contraction in normal weight and obese older adults. J. Gerontol. A Biol. Sci. Med. Sci. 2016, 71, 557-564. [CrossRef] [PubMed]

69. Boesch, C.; Kreis, R. Observation of intramyocellular lipids by $1 \mathrm{H}$-magnetic resonance spectroscopy. Ann. N. Y. Acad. Sci. 2000, 904, 25-31. [CrossRef] [PubMed]

70. Boesch, C. Musculoskeletal spectroscopy. J. Magn. Reson. Imaging 2007, 25, 321-338. [CrossRef] [PubMed]

71. Therkelsen, K.E.; Pedley, A.; Speliotes, E.K.; Massaro, J.M.; Murabito, J.; Hoffmann, U.; Fox, C.S. Intramuscular fat and associations with metabolic risk factors in the Framingham Heart Study. Arterioscler. Thromb. Vasc. Biol. 2013, 33, 863-870. [CrossRef] [PubMed]

72. Sinha, R.; Dufour, S.; Petersen, K.F.; LeBon, V.; Enoksson, S.; Ma, Y.-Z.; Savoye, M.; Rothman, D.L.; Shulman, G.I.; Caprio, S. Assessment of skeletal muscle triglyceride content by (1)H nuclear magnetic resonance spectroscopy in lean and obese adolescents: Relationships to insulin sensitivity, total body fat, and central adiposity. Diabetes 2002, 51, 1022-1027. [CrossRef] [PubMed]

73. Goodpaster, B.H.; Thaete, F.L.; Simoneau, J.A.; Kelley, D.E. Subcutaneous abdominal fat and thigh muscle composition predict insulin sensitivity independently of visceral fat. Diabetes 1997, 46, 1579-1585. [CrossRef] [PubMed]

74. Miljkovic, I.; Zmuda, J.M. Epidemiology of myosteatosis. Curr. Opin. Clin. Nutr. Metab. Care 2010, 13, 260-264. [CrossRef] [PubMed]

75. Strasser, E.M.; Draskovits, T.; Praschak, M.; Quittan, M.; Graf, A. Association between ultrasound measurements of muscle thickness, pennation angle, echogenicity and skeletal muscle strength in the elderly. Age 2013, 35, 2377-2388. [CrossRef] [PubMed]

(C) 2018 by the authors. Licensee MDPI, Basel, Switzerland. This article is an open access article distributed under the terms and conditions of the Creative Commons Attribution (CC BY) license (http:/ / creativecommons.org/licenses/by/4.0/). 